\title{
Research on Influences of International Trade on Regional Urban-Rural Income Gap in China
}

\author{
Burenmende \\ School of economics and management, Inner Mongolia University for the Nationalities, \\ Tongliao, 028000, China
}

Keywords: International trade; China regional economy; urban-rural income gap; dual economic structure

\begin{abstract}
As China's economic development is affected by dual economic structure, the urban-rural income gap is great. In addition to the endogenous factors, opening-up becomes an important issue that affects the urban-rural income gap among the factors causing this phenomenon. China's opening-up policy promotes the rapid development of international trade, leading to the increase of national income in successive years. However, China has been in a state of regional development for a long time and the development of international trade in different regions in unbalanced due to the unbalanced regional economy, thus causing great urban-rural income gap. The influences of international trade on regional urban-rural income gap in China are mainly discussed in this paper.

Since the reform and opening up in late the 1970s in China, the trade scale increases rapidly. In the 21st century, China joins WTO and the international trade plays an important role in regulating China's economy. With the development of economic globalization and affected by trade liberalization, the regional urban-rural income gap widens gradually, which has become a social issue to be solved urgently.
\end{abstract}

\section{International trade causes great urban-rural income gap in China}

From the proportion of urban-rural income gap in the income gap summary, it was more than $75 \%$ in 2006. China has conducted new socialist countryside construction and spared no efforts to solve the three rural issues, the urban-rural income cap is not solved substantially. From the development history of reform and opening up of China, 1978 was the first year of the reform and opening up of China, but it was in an exploratory stage and not completely open, in which the urban-rural income gap was 1:22; from 1978 to 1984, reform was not conducted in partial cities in China and the urban-rural income gap in 1984 was 1:1.6. Since 1984, the reform and opening up was in full swing and the foreign economy was stressed, leading to the widening of urban-rural income gap. By 2005, the urban-rural income gaps was 1:3.3. Since 2006, China has experienced 8 years' economic development and the urban-rural income gaps has been more than the international warning line of 0.4, reaching the Gini coefficient of 0.494 .

The economic globalization promotes the development of international trade, the national economy in China advances rapidly and the residents' income level is improved. However, the degree of opening and the trade mode are different in different regions, leading to unbalanced regional income distribution under the influences of international trade.

\section{International trade affects the current situation of regional urban-rural income gap}

(I) Development state of international trade in China

Since China joined WTO in 2001, the total volume of international trade has increased rapidly. In 2001, the total volume of international trade of China was USD 589 million and is USD 27943.55 now. Affected by global financial crisis, the total volume of international trade of China decreased in 2009, but recovered to the normal state soon. In 2003, the total volume of international trade of China increased greatly, which was stable with a linear growth. 
From the growth of international trade, the average annual growth rate of the volume of internal trade of China from 1978 to 2013 increased from 23.66\% to $24.13 \%$, the growth rate of imports was $22.97 \%$ and the average annual growth rate of GDP was $14.27 \%$. It is clear that driven by the reform and opening up, the growth rate of international trade of China has a cyclical trend: increase-decrease-increase-decrease.

The global trade develops. With the increase of the proportion of China's foreign trade, China's trade ranking rises to the second place from the 32nd place in 1978, with exports and imports ranking first. In the world trade, China has become the world's largest exporter and the second largest trading country now.

(II) Development state of urban-rural income gap

The urban-rural income gap in China at the present stage is caused by the unequal income distribution. With the rapid development of market economy, the disposable income in the income of urban residents increases and the growth of the income of rural residents is slow. Over the years, China's economy has kept prosperous development and the income gap between rural and urban residents fluctuates, which is more than two times. The widening of urban-rural income gap leads to unequal income distribution.

In addition, the income of urban residents increases stably, so the income gap between urban and rural residents widens continuously. Since the reform and opening up in 1978, the rural areas have a great change. The rural residents benefit first and its rapid development speed has been more than the income of urban residents. From the regional perspective, China's eastern regions are open first, so the resident income is higher than the middle and western regions. For example, in 2013, the farmers' income per capital was more than RMB 10,000 and the income of urban residents per capital was more than RMB 20,000 in eastern regions, the income ratio of rural and urban residents was 1:2.25; the urban-rural income gap in central regions widened with the economic growth, in which the farmers' income per capital was about RMB 5600 and the income of urban residents per capital was about RMB 15,500 , the income ratio of rural and urban residents was 1:2.68; the urban-rural income gaps in western regions was bigger, in which the farmers' income per capital was about RMB 4400 and the income of urban residents per capital was about RMB 15,300 , the income ratio of rural and urban residents was 1:3.44 beyond the warning line. According to the urban-rural income, the urban-rural income gap in western regions was the biggest, that in eastern regions was the smallest and that in central regions was obvious.

(III) Correlation between influences of international trade on regional urban-rural income gap

From the regional trade development, the international trade and the income gap between urban and rural residents are directly proportional, but inversely proportional in economically underdeveloped regions. Since the reform and opening up of China, the eastern coastal regions have developed first, in which the rapid development of economy promotes the frequent international trade and the urban-rural income gap widens year after year, indicating that the international trade and the urban-rural income gap in eastern regions are directly proportional. The economic development in central regions is slow and the western regions are under-developed. The trade development degree in eastern regions is high, leading to the close correlation between international trade and income gap between urban and rural residents. In addition, with the development of international trade, the income gap between urban and rural residents will further widen.

\section{Empirical analysis of the influences of international trade on regional urban-rural income gap in China}

(I) Regional economic development state in central regions

Taking central regions in China as an example, according to the geographic classification of international statistics, central regions cover nine provinces, including Inner Mongolia, Jilin, Heilongjiang, Jiangxi, Shanxi, Henan, Anhui, Hunan and Hubei. Since the 1990s, the reform and opening up of China entered an in-depth development stage and the "three rural" economy developed vigorously; however, the increase of urban-rural income gap became a critical issue. Entering the 21st century, the foreign trade of central regions accounted for $36 \%$ of the total volume 
of national foreign trade and its attracted foreign capital was up to $13 \%$ of the total national foreign capitals by virtue of the opportunity that China joined WTO. Compared with eastern regions, the development speed in central regions was slow and the reform and opening up degree was low, the development strategy of rise of central China put forward by Chinese government in 2004 deepened the reform and opening up degree and imposed significant influences on urban-rural income gap in central regions. Since 2005, the economic growth in central regions improved to a certain degree. By 2007, GDP was up to RMB 7048313 million in central regions, accounting for more than 29.24\% of gross GDP and the GDP per capital increased greatly, which was more than RMB 14,000 . With the increase of the total volume of regional foreign trade in central regions, the value of exports was USD 6.3 trillion and that of imports was USD 46627 million in 2010. With the holding of the 18th National Congress of the Communist Party of China, China entered the development state of in-depth reform and opening up and the total trade volume in central regions increased rapidly.

From the agricultural production status in central regions, other eight provinces except Shanxi are big agricultural provinces, in which the proportion of farmers is more than $57.9 \%$, accounting for $35.48 \%$ of gross farmers nationwide. From the international trade structure, central regions mainly import pesticide, fertilizer, electromechanical products and steels as well as various chemical materials and exports resource-intensive raw materials and labor-intensive products, which are mainly primary products. From the trade mode, the main trade mode in central regions is general trade and the processing trade accounts for a low proportion though it is the main export mode.

(II) Quantitative analysis of the influences of international trade on urban-rural income gap in central regions

At present, the academic circles think after analyzing the regional urban-rural income gap in central China that the factors influencing the successive widening of urban-rural income gap is mainly the dual economic structure and that the different educational level, regional disparity and growth speed of GDP impose different influences on urban-rural income. The regional urban-rural income gap in central China is studied and the regression model is built by stepwise regression method to analyze the influences on international trade in this paper.

The model is as follows:

DISPARITYi $=\mathrm{f}\{$ OPEN, i Xi $\}+$ ui

Where, DISPARITY is construed as a variable, whose role is to measure the gap by introducing the factors influencing the urban-rural income gap. The four important factors that affect the urban-rural income gap in central regions are set: DUAL (dual economic structure contrast coefficient)、EDU (educational development level)、GDP (gross domestic production)、 DUMMY (virtual variable). The dual contrast coefficient is analyzed and the relative labor productivity of agriculture and non-agriculture in central regions is compared to get the dual degree of regional economy. The educational development level is the proportion of state financial appropriation for education in GDP. For the virtual variable, the economically developed province is set as " 1 " and other provinces are set as " 0 " and it can be proved that the urban-rural income gap in central regions is big if the result is a negative number. During empirical analysis, logarithmic form is adopted for comparison except the virtual variable.

During the analysis of DUAL, EDU, GDP and DUMMY, the dependence of international trade is introduced.

Dependence of international trade $=$ total volume of foreign trade/GDP.

If the dependence of international trade is a positive number, it is proved that the increase of international trade has influences on the widening of the income gap between urban and rural residents.

The dependence of international trade is analyzed by regression model and the coefficient obtained is:

LDUAL=-0.121;

LEDU $=0.284$; 
LGDP=0.251;

LDUMMY $=0.092$.

The obtained trade coefficient is -0.116 .

After F test, the regression model is significant at 0.001 level. Thus, it can be known that the fitting degree of model is higher after introducing the dependence of international trade. The dependence of international trade is analyzed theoretically and it can be judged from the negative number that the introduction of international trade can narrow the income gap between urban and rural residents.

(III) Trade policy regulates and narrows the urban-rural income gap in central regions

The trade policy relieves the increase of the urban-rural income gap in central regions. With the further reform and opening up of China, it is required to adjust the industrial structure and promote the industrial upgrading to accelerate the regional economic development. To encourage the foreign investment, accelerate the high-tech industry and expand the exports, it is required to provide supports in capital, technology and human resources and guide the foreign investment in these industries. As a big agriculture country, the number of farmers in China is more than 900 million people. To encourage the agricultural opening up, it is required to continuously optimize the agricultural resources and technical structure, improve the quality and yield of agricultural products and relieve the agricultural economy pressure in eastern regions by expanding the exports of agricultural products. In addition, it is also required to make full use of the regional advantages, formulate capital attraction policy and increase the capital attraction strength in order to promote the foreign trade development in central regions.

\section{Conclusion:}

In conclusion,the urban-rural income gap in China increases gradually affected by many factors. From the actual situation of the regional economic development in China, to narrow the urban-rural income gap, the government should give full play to the positive role of international trade, establish unified capital element market and guide the international trade to narrow the regional urban-rural income gap.

\section{References}

[1] Lin Jiang, Huang Liangxiong, Sunhui. Is There An Inverted U-Shaped Relationship between Trade Opening Degree and Urban-Rural Income Gap-Non-Parametric Estimation Based on China’s Provincial Panel Data [J]. Academic Research, 2011(05).

[2] Sun Yongqiang, Wang Yulin. Resesarch on Relationship between Foreign Trade and Urban-Rural Income Gap in China-Empirical Analysis Based on Provincial Panel Data in 1978-2008[J]. Economic Survey, 2010(06).

[3]Elena Meschi. Trade and Income Inequality in Developing Countries [J]. Elsevier, 2009.37 ( 02 ) .

[4]Ethier, W. J. Globalization: Trade, technology and wage [J]. International Rene of Economics and Finance, 2005 (14).

[5] Liu Xiaoyun, Mao Xuefeng, Xin Xian. Influences of Liberalization of Agricultural Product Trade on China’s Rural Poverty[M]. Beijing: China Agriculture Press, 2006. 